\title{
Neues bei HIV und Neuro-Aids
}

\section{Update HIV-Infection and Neuro-Aids}

Autoren

Institute
G. Arendt ${ }^{1}$, O. Grauer ${ }^{2}$, K. Hahn ${ }^{3}$, M. Maschke ${ }^{4}$, M. Obermann ${ }^{5}$, I. W. Husstedt ${ }^{2}$

Klinik für Neurologie, Universitätsklinikum Düsseldorf

Klinik für Neurologie, Universitätsklinikum Münster

Klinik für Neurologie, Charité Berlin

${ }^{4}$ Klinik für Neurologie, Klinikum Trier

Klinik für Neurologie, Universitätsklinikum Essen
Schlüsselwörter

- HIV-Infektion

- Neuro-Aids

- HIV-assoziierte neurokognitive Störung

- Komorbiditäten

opportunistische Infektionen

Keywords

- HIV-infection

- neuro-aids

- HIV-associated neurocognitive disorder

- comorbidities

- opportunistic infecctions

\section{Bibliografie}

DOI http://dx.doi.org/ 10.1055/s-0035-1552692

Akt Neurol 2015; 42: 445-455

(c) Georg Thieme Verlag KG

Stuttgart · New York

ISSN 0302-4350

\section{Korrespondenzadresse}

\section{Univ.-Prof. Dr. I. W. Husstedt}

Klinik für Neurologie Universitätsklinikum Münster Albert-Schweitzer-Campus 1 48129 Münster

husstedt@uni-muenster.de

\section{Zusammenfassung \\ $\nabla$}

Trotz sehr effektiver Behandlungsoptionen für die systemische HIV-Infektion sind Neuro-Aids und die HIV-assoziierte neurokognitive Störung ein klinisches und alltagsrelevantes Problem. Man unterscheidet 3 Stufen, das HIV-assoziierte, neuropsychologische Defizit (ANPD), das milde, HIVassoziierte neurokognitive Defizit (MNCD) und die HIV-assoziierte Demenz (HAD). Die Behandlungsmöglichkeiten HIV-assoziierter neuro-kognitiver Störungen umfasst die antiretrovirale Therapie (cART), die den CPE-Score zur Penetration der Medikamente ins ZNS berücksichtigen sollte. Es ist sinnvoll, bei Auftreten multiresistenter Virusvarianten im Blut auch im Liquor entsprechende Untersuchungen durchzuführen. Im peripheren Nervensystems treten neben der klassischen, distal-symmetrischen, HIV-assoziierten Polyneuropathie immunogen vermittelte Neuropathien oder Myopathien auf (CIDP, AIDP). Durch die antiretrovirale Therapie (cART) verursachte Polyneuropathien sind differenzialdiagnostisch zu berücksichtigen. Erworbene mitochondrial toxische Myopathien treten häufiger auf, da nun eine cART durchaus über 10-20 Jahre durchgeführt wird. Bei Patienten mit schweren depressiven Episoden zeigte sich eine 6-mal höhere Wahrscheinlichkeit, die Einnahme der cART mindestens einmal zu vergessen. Depressive Episoden sind oft ein Grund für mangelhafte Adhärenz, korrelieren mit einer höheren Viruslast und sind dringend zu behandeln. In den letzten Jahren kam es infolge der verbesserten cART zu einem Rückgang der opportunistischen Infektionen (OI) des ZNS.

Die häufigsten OI stellen die progressive multifokale Leukoenzephalopathie (PML), die Toxoplasma-Enzephalitis und die Kryptokokken-Meningitis dar. Bei rasch progredientem Verlauf einer OI muss an ein Immunrekonstitutionssyndrom (IRIS) gedacht werden. Es gibt momentan keine

\section{Abstract \\ $\nabla$}

Despite very effective treatment options for HIVinfection, Neuro-Aids and neuro-cognitive disorders remain a problem. There are three stages: HIV-associated, neurocognitive impairment (ANI), mild, HIV-associated neurocognitive deficit (MNCD) and HIV-associated dementia (HAD). Antiretroviral combination therapy (cART) should take into account the CNS penetration effectiveness (CPE)-score of the antiretroviral drugs. CSFviral load and genetic virus variants should be analysed. There are also virus-associated complications of the peripheral nervous system. Besides the classic distal symmetrical, HIV-associated polyneuropathy, immunogenic neuropathies (CIDP, AIDP) and myopathies also occur. Polyneuropathies caused by cART represent a differential diagnosis. Acquired mitochondrial toxic myopathies occur more frequently, because nowadays cART is administered over 10-20 years. Depression, a frequent psychiatric complication, is associated with poor adherence and higher viral loads, and must be treated promptly. In recent years, the prevalence of opportunistic CNS-infections has declined due to the modern antiretroviral therapy. Progressive multifocal leucoencephalopathy (PML), Toxoplasma gondii encephalitis and Cryptococcus neoformans meningitis are the most common OIs. In case of rapidly progressive disease, an immune reconstitution syndrome (IRIS) should be considered. There is currently no reliable method to differentiate PML-deterioration from IRIS-PML. Because of a significantly increased life expectancy, comorbidities become more relevant. Neopterine as a marker of macrophage activation, neurofilament light protein and total tau protein represent biomarkers for disease activity in the CNS. 
sichere Methode, z. B. die Verschlechterung einer PML durch den natürlichen Krankheitsverlauf von der Verschlechterung durch ein IRIS zu unterscheiden. Infolge der deutlich zunehmenden Lebenserwartung treten Komorbiditäten mehr in den Vordergrund. $\mathrm{Zu}$ den viralen Biomarkern für die Krankheitsaktivität im ZNS zählen Neopterin als Marker der Makrophagenaktivierung, das Neurofilament-Leichtprotein und das Gesamt-Tau-Protein.

\section{Einleitung}

$\nabla$

Aus neurologischer Sicht hat sich in den letzten Jahren ein gewisser Wandel in der Versorgung HIV-Infizierter ergeben. Die Mehrzahl der Patienten ist durch eine chronische HIV-Infektion mit gut kompensiertem Immunstatus gekennzeichnet. Auch wenn die Dauer der HIV-Infektion und die CD4-Zellzahl einen guten klinischen Anhalt über die Immunkompetenz des Patienten geben, eignen sie sich doch nur bedingt zur Eingrenzung des differenzialdiagnostischen Spektrums, da die große Mehrzahl der Patienten stabile, häufig formal „normwertige“ $\mathrm{CD} 4^{+}$-Helferzellen erreicht, ohne dass dies einer physiologischen Immunkontrolle gleichzusetzen ist. Die HIV-Infektion ist eine behandelbare Erkrankung geworden, die bei guter Adhärenz die Lebenserwartung kaum mindert.

\section{Die HIV-assoziierte neurokognitive Störung (HAND) $\nabla$}

In der Prä-cART-Ära (vor der Einführung der modernen antiretroviralen Kombinationstherapien 1996) korrelierte die Prävalenz neurokognitiver Defizite HIV-Infizierter mit dem Abfall CD4 ${ }^{+}$-positiver Lymphozyten. 20-30\% der Betroffenen waren zum Zeitpunkt ihres Todes dement [1]. Die „klassische“ HIV-assoziierte Demenz ist durch motorische, kognitive und emotionale Defizite charakterisiert, die Patienten zeigen niemals eine Aphasie oder Apraxie. Heutzutage ist die Symptomausprägung milder [2]. Außerdem stehen statt wie früher motorische, meist kognitive Einbußen im Vordergrund, wobei allerdings nach wie vor die motorischen Symptome - insbesondere bei älteren Patienten - am sensitivsten Verschlechterungen erfassen [3]. Trotz der modernen antiretroviralen Kombinationstherapien treten bei HIVInfizierten auch heute noch neurokognitive Störungen auf, die seit einer Konsensuskonferenz 2005 in Frascati unter dem Begriff "HAND" (HIV-associated neuro-cognitive disorders) zusammengefasst [4] bzw. als „Frascati“-Kriterien bezeichnet werden. Man unterscheidet 3 Stufen, das HIV-assoziierte, neuropsychologische Defizit (ANPD), das milde, HIV-assoziierte neurokognitive Defizit (MNCD) und die HIV-assoziierte Demenz (HAD), denen bestimmte Definitionskriterien zugrunde liegen ( $\bullet$ Tab. 1).

Die Diagnosen dürfen nur gestellt werden, wenn pathologische neuropsychologische Testprofile in einem Mindestabstand von 4 Wochen gleichsinnig reproduziert werden können, d.h., es müssen dieselben Tests abnorme Ergebnisse zeigen.

\section{Anamnese, Fremdanamnese und Screening}

Zur Differenzierung zwischen aktiven und inaktiven „HAND“Stadien werden Anamnese und Fremdanamnese genutzt. Hierzu können speziell entworfene Fragebögen [5] herangezogen werden, die durch die Kombination mit Surrogatmarkern der HIV-Infektion eine gewisse Spezifität (im zitierten Fall 0,6218) erreichen.

Fragebögen wie der vorgenannte münden in einen Score, der Wahrscheinlichkeiten, neurokognitive Defizite zu haben, angibt, sodass diejenigen Patienten, die einer ausführlichen neuropsychologischen Testung unterzogen werden sollten, erfasst werden. Im Falle des vorgenannten Fragebogens ist ein Score-Wert bei $>7$ prädiktiv für kognitive Einbußen.

Auch ANPD und MNCD sowie die heute vorherrschende, attenuierte Form der HAD haben negative Auswirkungen auf den Erfolg im Beruf, die Therapietreue und somit auf das Überleben der Patienten. Es wird kontrovers diskutiert, ob ein „Screening“ bei jedem HIV-positiven Patienten durchgeführt werden sollte, wie in einer Konsensuspublikation aus dem Jahr 2013 [6] empfohlen wurde, oder ob dies primär auf Patienten mit subjektiven kognitiven Defiziten zu beschränken ist.

In jedem Fall sollten vor der Einleitung weiterer diagnostischer Schritte aktiver Drogengebrauch (Urinuntersuchung) und andere psychiatrische Erkrankungen ausgeschlossen werden. Auch Nebenwirkungen der antiretroviralen Therapie (die Einnahme von Efavirenz kann zu Depressionen, einigen Publikationen zufolge [7] bei Langzeitbehandelten auch zu kognitiven Einbußen führen) müssen differenzialdiagnostisch in Betracht gezogen werden.

\section{Diagnostische Methoden}

Nach Ausschluss bzw. unter Berücksichtigung von Komorbiditäten (z. B. auch einer Hepatitis-Virus-C-Ko-Infektion) sollten HIVpositive Patienten in einem ersten diagnostischen Schritt einer neuropsychologischen Testung entsprechend den „Frascati“-Kriterien unterzogen werden, also mindestens 5 Tests absolvieren, die zeitabhängig sein und z.B. Aufmerksamkeit, psychomotorische Geschwindigkeit, mentale Flexibilität und räumlich-konstruktive Fähigkeiten erfassen sollten. Hierfür geeignet sind u.a.:

- der Trail-Making-Test Form A+B

- der Digit-Symbol-Test

- der Stroop-Colour-Word-Test

- der Wisconsin-Card-Sorting-Test

- der Grooved-Pegboard-Test sowie

die Testung der formal-lexikalischen und semantisch-kategoriellen Wortflüssigkeit, wobei - je nach Ausstattung der Institution auch ausgedehntere Testbatterien zur Anwendung kommen können.

Sind weniger als 2 von mindestens 5 Tests auffällig, empfiehlt sich eine Kontrolle in 6-12 Monaten, bei pathologischen Resultaten in 2 Tests in 3-6 Monaten, bei mehr als 2 pathologischen Tests ist die Diagnostik um - falls noch nicht erfolgt - eine ausführliche neuropsychologische Testung, ein kraniales Kernspin-

\begin{tabular}{|lllll|}
\hline & $\begin{array}{l}\text { keine vorbeste- } \\
\text { hende Ursache }\end{array}$ & kein Delir & $\begin{array}{l}\text { erworbenes Defizit in } \\
\mathbf{2} \text { kognitiven Domänen }\end{array}$ & $\begin{array}{l}\text { Behinderung } \\
\text { im Alltag }\end{array}$ \\
\hline $\begin{array}{l}\text { asymptomatisches neuro- } \\
\text { psychologisches Defizit (ANPD) }\end{array}$ & $\checkmark$ & $\checkmark$ & $\checkmark$ & nein \\
\hline $\begin{array}{l}\text { mildes neurokognitives } \\
\text { Defizit (MND) }\end{array}$ & $\checkmark$ & $\checkmark$ & $\checkmark$ & wenig \\
\hline HIV-assoziierte Demenz (HAD) & $\checkmark$ & $\checkmark$ & immer & schwer \\
\hline
\end{tabular}

Tab. 1 AAN-Definitionen der HIV-assoziierten neurokognitiven Erkrankungen (HAND) von 2007 [4]. 


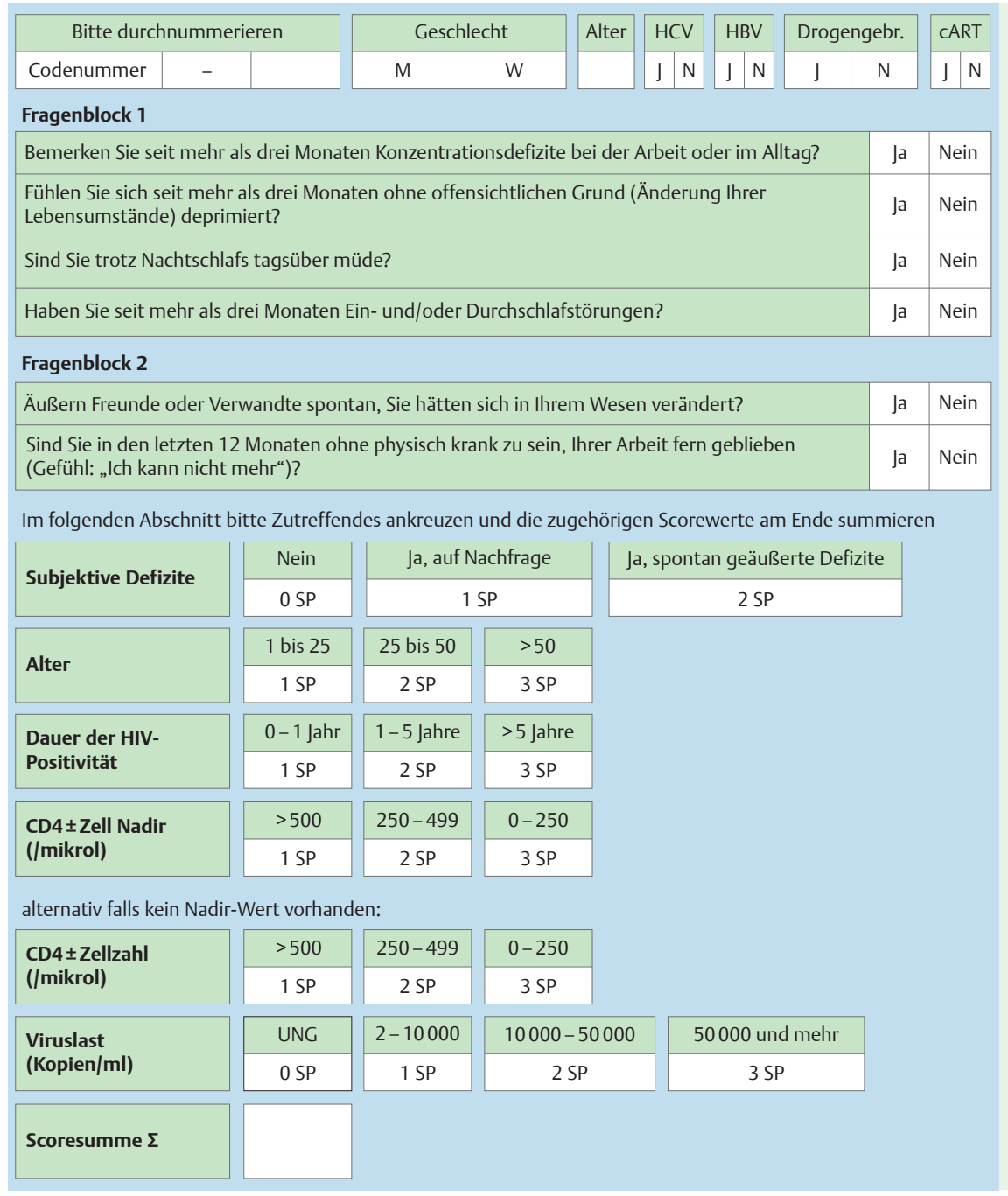

Abb. 1 Modifiziert nach Arendt [5].

tomogramm und eine Lumbalpunktion mit Bestimmung der HIViruslast im Liquor sowie ggf. einem Resistenzprofil zu erweitern.

\section{Bildgebende Diagnostik}

Die kraniale Kernspintomografie ist in der klinischen Routine die Methode der Wahl; sie schließt zerebrale opportunistische Infektionen (Zytomegalie-Virus-Enzephalitiden, JC-Virus-Infektionen, Toxoplasma-gondii-Abszesse) und zerebrale Lymphome aus und weist häufig - vor allem in den T2-gewichteten und FLAIR-Sequenzen - fleckförmige Echoanhebungen in den hemisphärischen Marklagern und/oder den subkortikalen Kernstrukturen oder flächige, periventrikulär betonte, hyperintense Zonen ohne Entsprechungen in den T1-Wichtungen nach; es handelt sich bei diesen Befunden nicht um Entmarkungen, sondern um interstitielle Wasseransammlungen, die unter einer antiretroviralen Kombinationstherapie rückläufig sein können [8]. Ausgeprägte kernspintomografische Veränderungen sind im Zeitalter der cART selten geworden; in den weltweit alternden Kohorten (man rechnet damit, dass 2017 knapp über 50\% aller HIV-Positiven älter als 50 Jahre sein werden) sind sie von vaskulären Erkrankungen (subkortikale arteriosklerotische Enzephalopathie) abzugrenzen, was im Einzelfall schwierig sein kann, zumal viele HIV-Patienten ein breites vaskuläres Risikoprofil haben. Hilfreich kann eine Kernspinspektroskopie (MRS) sein; man kann mit dieser Methode über reduzierte N-Acetyl-D-Aspartat-Spiegel eine
Beeinträchtigung neuronaler Zellfunktionen nachweisen, ebenso über erhöhte Gliazell-Marker (Myoinositol, Cholin) eine Zellmembrandysfunktion, eine erhöhte zelluläre „Turnover“-Rate bzw. eine Gliazellaktivierung [9]. Diese Befunde sind unter einer cART ebenfalls reversibel, allerdings nicht so schnell wie der Abfall der $\mathrm{CD}^{+}{ }^{+}$-Zellen oder der Anstieg der Liquor-Viruslast. Mit der MRS kann man auch neurotoxische Nebenwirkungen einer Langzeit-cART nachweisen [10], wobei die klinische Bedeutung dieser spektroskopischen Messergebnisse noch unklar ist.

\section{Befunde im Liquor}

Unter einer CART sind Pleozytosen und Gesamtproteinerhöhungen meistens rückläufig, IgG-Erhöhungen und oligoklonale Banden persistieren häufig im Liquor. Allgemein akzeptierte Biomarker gibt es nicht, aber die Bestimmung der Liquor-Blut-AlbuminRatio und des Neopterins lässt Rückschlüsse auf den Funktionszustand der Blut-Hirn-Schranke und eine intrathekale Immunaktivierung in Frühstadien der HIV-Infektion (ANPD, MNCD) zu $[11,12]$, ebenso wie die Bestimmung der Neurofilament-Leichtkettenproteine in Spätstadien (HAD) neuronale Zelldysfunktionen indizieren kann [13]. Die Bestimmung der HI-Viruslast im Liquor korreliert nicht immer positiv mit klinischen Symptomen oder neuropsychologischen Defiziten, ist nicht selten in Anwesenheit opportunistischer Erreger erhöht und normalisiert sich nach erfolgreicher Behandlung des jeweiligen Erregers. Etwa $10 \%$ der HIV-Infizierten zeigen im Liquor ein „viral esca- 
pe“-Phänomen, d.h., eine Virusreplikation im Liquor trotz effektiver Suppression im Blut oder eine höhere Virusreplikation im Liquor im Vergleich zum Blut [14]. In solchen Fällen muss man eine Resistenzanalyse der Liquor-Virusvarianten durchführen lassen, um Diskordanzen erfassen und die antiretrovirale Therapie anpassen zu können (zu weiteren Einzelheiten siehe auch Abschnitt „Besonderheiten der Liquordiagnostik bei HIV-Infektion).

\section{Kofaktoren}

Es gibt demografische und HIV- oder therapieassoziierte Kofaktoren HIV-assoziierter Gehirnerkrankungen, die zudem durch genetische virus- oder wirtimmanente Eigenschaften, SchädelHirn-Traumata in der Vorgeschichte, epileptische Anfälle, Drogen- und Alkoholabhängigkeit bzw. Vitamin- oder Hormonmangelzustände beeinflusst werden können. Demografische Kofaktoren sind Alter [3], mangelnde Bildung sowie fehlender Zugang zu den modernen antiretroviralen Therapien [15]. Direkt virusassoziierte Kofaktoren sind: lange Dauer der HIV-Positivität, niedriger $\mathrm{CD}^{+}$-Zell-Nadir, niedrige aktuelle $\mathrm{CD}^{+}$-Zellzahlen [16], eine hohe Plasma-Viruslast [17] und zerebrale, opportunistische Infektionen in der Vorgeschichte [18]. Shiramizu et al. fanden eine gute Korrelation zwischen HAND und der Virus-DNA in infizierten Monozyten [19], therapieassoziierte Kofaktoren sind: niedrige Therapietreue, suboptimale Behandlung mit im Blut und/oder Liquor nachweisbarer Viruslast bzw. Therapieunterbrechungen [20], ein geringer „CNS-Penetration-Effectiveness“Score [21] sowie die potenzielle Neurotoxizität der antiretroviralen Therapie [22].

Kandidatengene mit einer Korrelation zu neurokognitiven Defiziten sind das Mannose bindende Lectin-2=MBL2 und APOE e4 [23], virale Gene mit Bezug zur Kognition sind die CD4+-binding site des envelope-Gens, das Transaktivatorgen („tat“) und das „viral protein“(Vpr).

\section{Komorbiditäten}

Richtunggebende Komorbiditäten für die Entwicklung neuro-kognitiver Störungen sind psychiatrische Erkrankungen, insbesondere Depressionen, die präexistent sein, infektionsassoziiert auftreten oder Therapiefolge sein können, Hepatitis-Virus-C-Konfektionen, eine floride Syphilis, kardiovaskuläre Ereignisse in der Vorgeschichte bzw. ein breites vaskuläres Risikoprofil, Anämien oder Thrombozytopenien [24], das Immun-Rekonstitutions-Syndrom (IRIS) und neurodegenerative Erkrankungen, die zudem wichtige Differenzialdiagnosen beim alternden HIV-Patienten sind. Komorbiditäten beeinflussen das Auftreten HIV-assoziierter neurokognitiver Störungen so deutlich, dass sie im Rahmen der „Frascati-Kriterien“ Berücksichtigung finden, d.h., sie sind zusätzlich zu vermerken (zu weitere Einzelheiten siehe Abschnitte „Depressive Episoden, Bedeutung von Komorbiditäten“).

\section{Differenzialdiagnosen}

Die wichtigsten Differenzialdiagnosen sind neurodegenerative (M. Alzheimer, M. Pick, u.a.), vaskuläre und prioneninduzierte Demenzen. Sie sind durch klinische und neuropsychologische Untersuchungen sowie durch den gezielten Einsatz technischer Zusatzmethoden (EEG, Bildgebung und Liquoranalysen) abzugrenzen. So haben Alzheimer-Kranke Hirnwerkzeugstörungen, die bei Patienten mit einer HIV-assoziierten Demenz - wie oben bereits erwähnt - selten zu finden sind. Die Positronen-Emissions-Tomografie zeigt bei Alzheimer-Patienten den kortikalen Hypometabolismus, aber keine subkortikalen Stoffwechselveränderungen, wie sie für die HIV-assoziierte Demenz typisch sind (initial Hyper-, im Vollbild der Demenz Hypometabolismus). Liquorbefunde differenzieren nicht, da erhöhte Tau-Proteine und ein vermindertes Amyloid $A \beta 42$ bei beiden Erkankungen vorkommen können.

Am schwierigsten ist eine vaskuläre Demenz von HIV-assoziierten Veränderungen abzugrenzen, solange sie nicht mit Schlaganfällen einhergeht, sondern sich als subkortikale, arteriosklerotische Enzephalopathie (SAE) präsentiert, zumal HIV-Patienten nicht selten ein therapieinduziertes, metabolisches Syndrom haben. Sorgfältige MRT-Analysen des Verteilungsmusters der subkortikalen Herde (bei HIV-Patienten liegt der Schwerpunkt in den subkortikalen Kernstrukturen) können hier hilfreich sein.

Andere Demenzformen sind durch charakteristische klinische Symptome (M. Pick, Prionenerkrankungen) mit entsprechenden Zusatzbefunden (z.B. EEG-Rademaker-Komplexe bei Prionenerkrankungen) leichter zu differenzieren.

Therapie

Die Behandlungsmöglichkeiten HIV-assoziierter neurokognitiver Störungen umfasst die antiretrovirale Therapie, die den CPEScore [21] berücksichtigen sollte. Es ist sinnvoll, bei Auftreten multiresistenter Virusvarianten im Blut auch im Liquor entsprechende Untersuchungen durchzuführen, falls die Kopienzahlen in diesem Kompartiment ausreichend sind (für die meisten Laboratorien gilt: mindestens $100 \mathrm{c} / \mathrm{ml}$ ).

Als adjuvante Therapie ist Memantin zur Behandlung der HAD in verschiedenen Studien als positiv bewertet worden, besitzt jedoch keine Zulassung und muss daher ggf. als individueller Heilversuch eingesetzt werden.

\section{HIV-assoziierte Polyneuropathien und Myopathien $\nabla$}

Das periphere Nervensystem stellt mit die häufigste HIV-assoziierte Organbeteiligung dar. Neben der klassischen, distal-symmetrischen, HIV-assoziierten Polyneuropathie (DSP) treten in vermehrte Ausmaß immunogen vermittelte Neuropathien oder Myopathien auf. Toxische Neuropathien entstehen durch den langjährigen Einsatz antiretroviraler Substanzen (antiretroviral toxische Neuropathien=ATN), resultieren aber auch aus der Anwendung von Chemotherapeutika bei der Behandlung von Tumorerkrankungen z. B. durch Vincristin. Die distal-symmetrische Polyneuropathie mit sensiblen Defiziten und Reizsymptomen stellt die häufigste Manifestation dar. Da einheitliche Diagnosekriterien fehlen, schwanken die Angaben zur Prävalenz zwischen 30 und 60\% [25]. Die Mehrzahl der Patienten mit einer ATN entwickelt diese innerhalb der ersten 3 Monate nach Einnahme einer antiretroviral-toxischen Substanz, während nach ca. einjähriger beschwerdefreier Einnahme keine ATN mehr zu erwarten ist [26]. Typische Substanzen, die eine ATN verursachen können, sind neben Stavudin und Didanosin auch die Proteaseinhibitoren [27]. Die ATN als auch die HIV-DSP zeigen ähnliche klinische Charakteristika mit dem neuropathischen Schmerz als verbindendes Element. Eine gemeinsame Grundlage scheint eine Schädigung der Neurone im dorsalen Spinalganglion (DRG) durch virale Proteine und proinflammatorische von HIV-infizierten Makrophagen produzierten Substanzen zu sein [28]. Tiermodelle der kombinierten NRTI/HIV-gp120-Protein-induzierten Neuropathie konnten ähnliche molekulare Mechanismen herausarbeiten. Diese umfassen neben proinflammatorischen Zytokinen, Chemokine, oxidativen Stress, MAPK und Veränderungen der Kalziumhomöostase [29]. Therapien des HIV-induzierten 
neuropathischen Schmerzes werden daher in der Zukunft v.a. auch diese Punkte adressieren. Die Chemokine MCP1 und SDF1 und deren Rezeptoren CCR2 und CXCR4 scheinen eine relevante Rolle zu spielen [30]. Mittels des CXCR4-Antagonisten AMD3100 konnte neuropathischer Schmerz im Tiermodell positiv beeinflusst werden [31]. Ein anderer neuer und vielversprechender experimenteller Ansatz ist die Neutralisation von TNF- $\alpha$ über lösliche neutralisierende TNF- $\alpha$-Rezeptoren [32] und damit verbunden die signifikante Reduktion einer mechanischen Allodynie im Nagermodell. Bisherige, in der Klinik zur Anwendung kommende symptomatische Therapien beschränken sich jedoch auf den Einsatz von Gabapentin [33], Pregabalin, Lamotrigin bei der ATN, Amitriptylin, Duloxetin und Opiate [34]. Auch topische Substanzen wie $8 \%$ Capsaicin sind signifikant wirksam und besitzen keine Interaktionen mit anderen Substanzen [35]. Eine Wirksamkeit der kombinierten antiretroviralen Therapie (CART) bei Vorliegen einer HIV-DSP konnte unabhängig von einer kleinen Fallserie [36] bisher nicht belegt werden.

Auch wenn systematische Untersuchungen fehlen, existieren Fallserien, die implizieren, dass HIV-Infizierte ein erhöhtes Risiko für immunvermittelte, demyelinisierende Neuropathien aufweisen, welche akut (AIDP) oder chronisch (CIDP) verlaufen können $[37,38]$. Dies sollte differenzialdiagnostisch bei Patienten mit relevanter motorischer Beeinträchtigung erwogen werden. Wie auch bei den nicht HIV-assoziierten Varianten zeigen sich elektrophysiologisch Hinweise auf eine erworbene Demyelinisierung mit dem Nachweis von Leitungsblöcken oder aber temporaler Dispersionen. Eine komorbide, sensible, HIV-assoziierte Neuropathie (HIV-DSP oder ATN) kann das typische klinische Erscheinungsbild unterlagern. Da bereits ca. zwei Drittel der HIV-Infizierten unabhängig von neurologischen Symptomen ein entzündliches Liquorsyndrom aufweisen, findet sich dies entsprechend überzufällig häufig und weicht somit vom typischen Liquorbefund einer isolierten Blut-Liquor-Schrankenstörung ab.

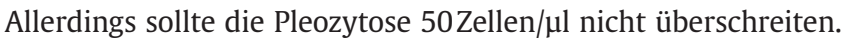
Patienten mit einem weit fortgeschrittenen Immundefektsyndrom mit CD4-Helferzellen $<50 / \mu l$ und akuten bis subakuten, häufig aufsteigenden Paresen sollten immer auch eine breite Liquordiagnostik bzgl. einer opportunistischen Infektion oder oder Tumorerkrankung, insbesondere einer Zytomegalievirusinfektion bzw. eines Lymphoms, erhalten.

Therapien orientieren sich an den nicht HIV-assoziierten, immunogenen Neuropathien und umfassen intravenöse Immunglobuline bzw. Plasmapheresen für die AIDP bzw. zusätzlich auch Kortikosteroide für die CIDP [25].

Seltener, aber klinisch relevant sind peripher-nervöse Erkrankungen, die mit einer motorischen Tetrasymptomatik und häufig assoziierten Myalgien einhergehen. Differenzialdiagnostisch sollte bei diesen Patienten an eine erworbene mitochondrial toxische Myopathie auf dem Boden einer langjährigen NukleosidaseReverse-Transkriptase-Inhibitoren (NRTI) enthaltenden, antiretroviralen Therapie gedacht werden. Elektromyografisch zeigen sich häufig allenfalls minimale myopathische Veränderungen, nicht selten ein Normalbefund. Die Kreatinphosphokinase ist häufig normal oder nur gering erhöht. Um diese Verdachtsdiagnose zu bestätigen, ist zumeist eine Muskelbiopsie notwendig, welche in der COX/SDH-Färbung oder aber elektronenmikroskopisch typische Veränderungen zeigt. Details gehen über den Anspruch dieser Zusammenfassung hinaus und sind in einem aktuellen Review zusammengefasst [39].
Tab. 2 Husstedt (modifiziert nach [41]). Psychiatrische Nebenwirkungen antiretroviraler Medikamente [Fachinformation zum jeweiligen Produkt auf den Webseiten der EMA].

\begin{tabular}{|ll|}
\hline $\begin{array}{l}\text { Nebenwirkungen } \\
\begin{array}{l}\text { Depression, Nervosität, } \\
\text { emotionale Labilität }\end{array}\end{array}$ & $\begin{array}{l}\text { AZT, d4T, 3TC, ABC, FTC, EFV, } \\
\text { alle PIs, MVC, RAL, RLP }\end{array}$ \\
\hline $\begin{array}{l}\text { Schlaflosigkeit } \\
\text { alle PIs, RAL, RLP }\end{array}$ \\
\hline $\begin{array}{l}\text { Suizidgedanken } \\
\text { Euphorie, Manie, aggressive } \\
\text { Reaktionen }\end{array}$ & EFV, NFV, RAL \\
\hline Angst, Konfusion, Verwirrtheit & AZT, d4T, ABC, EFV, SQV, NFV, \\
\hline $\begin{array}{l}\text { Depersonalisation, Halluzinatio- } \\
\text { nen, paranoide Reaktionen, } \\
\text { Psychosen }\end{array}$ & RTV, LPV, RAL \\
\hline $\begin{array}{l}\text { abnormales Denken/Träume } \\
\text { EbV, RTV }\end{array}$ & d4T, ABC, FTC, EFV, RTV, LPV, \\
\hline
\end{tabular}

Abkürzungen: $A B C=A b a c a v i r ; A Z T=A z i d o t h y m i d i n ; d 4 T=S t a v u d i n ; E F V=E f a v i r e n z$, $\mathrm{FTC}=$ Emritriciabin; $\mathrm{LPV}=$ Lopinavir, NFV = Nelfinavir; PI = Protease-Inhibitor; $\mathrm{RTV}=\mathrm{Ri}-$ tonavir; SQV = Saquinavir; TPV = Tipranavir; $3 \mathrm{TC}=$ Lamivudin; $\mathrm{MVC}=$ Maraviroc; $\mathrm{RAL}=$ Raltegravir; RLP= Rilpivirin

\section{Depressive Episoden}

\section{$\nabla$}

Eine Studie in Dänemark ergab, dass 38\% der Studienteilnehmer unter Symptomen einer Depression litten und bei 26\% eine schwere Depression festgestellt wurde, was die Wahrscheinlichkeit, die Einnahme von cART zu vergessen, wesentlich erhöht $[40,41]$. Depressive Episoden sind oft ein Grund für eine mangelhafte Adhärenz und korrelieren mit einer höheren Viruslast $[40,41]$.

Leichte depressive Episoden treten bei $25 \%$ der Patienten auf, schwere depressive Episoden bei $14 \%$ [42]. Auslöser für psychische Störungen können die HIV-Infektion sowie Antibiotika und antiretrovirale Medikamente sein ( $\bullet$ Tab.2).

Frauen sind von depressiven Episoden häufiger betroffen und weisen dann eine doppelt so hohe Wahrscheinlichkeit auf, an Aids zu versterben [43]. Ob unter Efavirenz ein erhöhtes Suizidrisiko besteht, wird momentan kontrovers diskutiert [44]. Viele Patienten mit depressiven Episoden erleben meist diffuse körperliche Beschwerden oder Schmerzen als im Vordergrund stehend. Niedergeschlagenheit und Angst werden dagegen primär nur in $7 \%$ bzw. $4 \%$ der Fälle angegeben. Weitere unspezifische Symptome, hinter denen sich eine depressive Episode verbergen kann, sind z.B. verminderte körperliche Leistungsfähigkeit, diffuse, schlecht lokalisierbare Schmerzen, Verdauungsbeschwerden, Schlafstörungen und Schwindel [45]. Nach Abklingen der Depression sollte die Behandlung noch weitere 3-6 Monate fortgesetzt und im Anschluss langsam ausgeschlichen werden [46]. Selektive Serotonin-Wiederaufnahmehemmer (SSRI) werden gegenüber tri- oder tetrazyklischen Antidepressiva oft bevorzugt, weil sie wesentlich weniger Nebenwirkungen aufweisen [41, 46, 47]. Für Serotonin-Wiederaufnahmerhemmern ist belegt, dass sie die Adhärenz auf das Niveau von Patienten ohne depressive Episode erhöhen [47-49].

Es ist Standard, die medikamentöse Therapie durch psychotherapeutische Verfahren und den Kontakt zu Selbsthilfegruppen (z. B. AIDS-Hilfe) zu ergänzen [41]. 


\section{Opportunistische Infektionen und inflammatorisches Immunrekonstitutionssyndrom (IRIS) \\ $\nabla$}

In den letzten Jahren kam es infolge der verbesserten systemischen Therapie mit Einführung neuerer Substanzen und Kombinationstherapien (cART) zu einem deutlichen Rückgang der opportunistischen Infektionen des zentralen oder peripheren Nervensystems [50]. Etwa ein Drittel der Infektionen treten bei CD4 ${ }^{+}$-Zellzahlen unter 200/ $\mu$ l auf. Eine hohe HI-Viruslast über 100000 RNA-Kopien/ml ist ein unabhängiger Risikofaktor für die Entstehung einer opportunistischen ZNS-Infektion. In den letzten Jahren werden jedoch vermehrt atypische Verläufe opportunistischer ZNS-Infektionen beobachtet. Zudem scheint es gerade nach Initiierung einer cART häufig zu entzündlichen Erkrankungen des zentralen und peripheren Nervensystems, aber auch innerer Organe zu kommen. Die daraus resultierenden Erkrankungen können inflammatorische Immunrekonstitutionssyndrome (IRIS) sein [51, 52]. Diese IRIS sind teilweise sehr schwer von der eigentlichen opportunistischen Infektion abzugrenzen, sodass häufig ein diagnostisches und daraus resultierend therapeutisches Dilemma entsteht. In diesen Fällen ist eine stereotaktische Biopsie oft indiziert und wegweisend.

\section{Opportunistische Infektionen}

Neuere Kohortenstudien zeigen, dass die Inzidenz opportunistischer Infektionen bei HIV-Patienten geringer geworden ist. So konnte die UK Collaborative HIV Cohort (CHIC) Study nachweisen [53], dass die Inzidenz aller ZNS-Komplikationen inklusive der opportunistischen Infektionen von 13,1/1000 Patientenjahre im Jahr 1996/1997 auf 1,0/1000 Patientenjahre in 2006/2007 drastisch abnahm [53]. Die häufigsten Infektionen waren die progressive multifokale Leukoenzephalopathie (PML) (0,7/1000 Patientenjahre), die Toxoplasma-Enzephalitis (0,4/1000 Patientenjahre) gefolgt von der Kryptokokken-Meningitis (0,2/1000 Patientenjahre).

Ein kürzlich publiziertes Review [54] wies darauf hin, dass sich die Epidemiologie der opportunistischen Infektionen aber auch je nach Region sehr unterscheiden kann. So gehört z.B. die tuberkulöse Meningitis in Afrika zu den häufigsten Infektionen bei HIV positiven Patienten. Die Kryptokokken-Meningitis ist weltweit mit mehr als 1 Million Fälle und 625000 Toten pro Jahr eine der häufigsten Pilzinfektionen des Gehirns. In der Therapie blieb zum einen unklar, ob die Kombinationstherapie Amphotericin B und Flucytosin besser wirksam ist als die Monotherapie mit Amphotericin B. Zudem ist Flucytosin nicht in allen Teilen der Welt problemlos erhältlich, sodass Fluconazol bereits in der Induktionstherapie eine billigere und besser erhältliche Therapie darstellen könnte. In einer kürzlich publizierten Studie wurde untersucht, ob Amphotericin B+Flucytosin oder Amphotericin B+Fluconazol der Monotherapie mit Amphotericin B überlegen ist [55]. Die Mortalität lag nach 14 und 70 Tagen in der Gruppe, die die Kombinationstherapie mit Amphotericin B+Flucytosin (Gruppe 1; 15 bzw. 30 Todesfälle; OR für Überleben 0,85 bzw. 0,69) erhielt, signifikant niedriger als bei der Monotherapie mit Amphotericin B (Gruppe 2; 25 bzw. 44 Todesfälle, OR für Überleben 0,75 bzw. 0,56 ) und der Kombinationstherapie Amphotericin B und Fluconazol (Gruppe 3; 20 bzw. 33 Todesfälle, OR für Überleben 0,80 bzw. 0,67). Nach dieser doppelblind-randomisierten Studie ist die Kombinationstherapie Amphotericin B plus Flucytosin in der Induktionsbehandlung der Kryptokokken-Meningitis bei HIV-erkrankten Patienten somit effektiver als die Monotherapie mit Amphotericin B, die Kombinationstherapie Amphotericin B+Flu- conazol ist hingegen der Monotherapie mit Amphotericin B nicht überlegen.

Neue Ergebnisse gab es zu prädisponierenden Faktoren für die Entstehung einer PML unter HIV. So zeigte eine kürzlich veröffentlichte Studie, dass bei Patienten mit PML L-Selectin (CD62 L) auf $\mathrm{CD}^{+}$-Zellen geringer exprimiert ist als bei HIV-Patienten ohne PML [56]. Insofern könnte L-Selectin eventuell zukünftig als Biomarker für die Risikobestimmung der Entwicklung einer PML dienen.

Inflammatorisches Immunrekonstitutionssyndrom (IRIS) Infektiöse IRIS entstehen auf dem Boden einer aktiven oder subklinischen opportunistischen Infektion. Infektiöse IRIS sind bei Weitem die häufigste Manifestation des IRIS. Dies scheint v.a. dann der Fall zu sein, wenn die zugrunde liegende Infektion sehr ausgeprägt ist [51]. Durch ein infektiöses IRIS entsteht klinisch häufig ein Bild, welches nicht oder nur sehr schwer von einer gewöhnlichen opportunistischen Infektion zu unterscheiden ist. Die bisher berichteten atypischen Infektionen, die auftreten, finden sich nach Infektion mit Mycobacterium-avium-Komplex (MAC), Mycobacterium tuberculosis, Cryptococcus neoformans, Pneumocystis carinii, Hepatitis B und C, Zytomegalievirus, Varicella-zoster-Virus, Herpes-simplex-Virus und JC-Virus. Darüber hinaus scheint es noch eine ganze Reihe sehr seltener infektiöser IRIS, z.B. nach Infektion mit Toxoplasmose, Parvovirus Typ B19 oder Chlamydia trachomatis zu geben.

Bei wenigstens 18\% der Patienten mit der Erstdiagnose einer PML kam es zu einem unerwarteten atypischen Verlauf [54]. Bei einem Teil der Patienten ergab die Kernspintomografie des Gehirns Kontrastmittelanreicherungen innerhalb der Läsionen, welches vor der cART-Ära ein eher seltener Befund war. In autoptischen Untersuchungen ergaben eine perivaskuläre Infiltration gerade von $\mathrm{CD}^{+}$-Zellen, Monozyten und Plasmazellen, was auf ein IRIS als Ursache der raschen Progression mancher PML-Fälle schließen lässt $[51,52,57]$. Eine andere Studie zeigte, dass die PML-IRIS dadurch hervorgerufen wird, dass CD8 ${ }^{+}$-Zellen die Dissemination von JC-Viren zwar reduzieren, es dabei aber zum Verlust von Oligodendrozyten und $\mathrm{zu}$ einer Demyelinisierung kommt [58]. Es gibt momentan keine sichere Methode, die Verschlechterung einer PML durch den natürlichen Krankheitsverlauf von der Verschlechterung durch ein IRIS zu unterscheiden $[52,59]$. Möglicherweise können die Bestimmung der quantitativen JC-Viruslast im Liquor und der Verlauf dieser Viruslast unter Therapie ausschlaggebend sein.

In der Zeit vor cART verursachte die Infektion mit Cryptococcus neoformans zumeist eine sehr ausgeprägte Meningitis, die bei vielen Patienten nur schlecht durch eine antimykotische Therapie beherrschbar war. Unter cART werden jetzt häufig Patienten beobachtet, bei denen es zu einer ungewohnt hohen Zellzahl im Liquor bei einer Kryptokokken-Meningitis kommt. Wie bei allen Patienten mit einem infektiösen IRIS scheint dies v.a. bei den Patienten zuzutreffen, die eine gute Immunrekonstitution haben, d.h. einen raschen Anstieg der $\mathrm{CD} 4^{+}$-Zellen und einen raschen Abfall der Viruslast im Blut [60]. Neben der Verschlechterung einer Kryptokokken-Meningitis kann es auch zu einer sehr ausgeprägten Lymphadenitis kommen. In Einzelfällen wurde nach einer Gabe von Kortikosteroiden eine Verbesserung des kryptokokkenassoziierten infektiösen IRS berichtet [61, 62].

Es ist derzeit noch nicht gut beantwortet, wie man therapeutisch auf das Vorliegen einer infektiösen IRIS reagieren kann. Nach Einzelfallberichten und kleineren Fallsammlungen kommt es nach der Gabe von Kortison, das theoretisch zur Suppression des über- 
schießenden Immunprozesses führen könnte, zu keiner sicheren Verbesserung infektiöser IRIS. Es gibt Hinweise, dass die Unterbrechung oder Modifizierung einer cART ein besseres Outcome zumindest bei der JC-Virus-assoziierten IRIS erreichen kann. Eine allgemeine Therapieempfehlung lässt die derzeitige Studienlage jedoch nicht zu. Inwieweit neuere Substanzen wie der Entry-Inhibitor Maraviroc, der als selektiver Inhibitor den menschlichen Chemokinrezeptor CCR5 blockiert, zu einer Verminderung der PML-IRIS führen könnte, ist bei Patienten mit HIV noch nicht untersucht. Bei Patienten mit multipler Sklerose und PML-IRIS gibt es jedoch erste Hinweise, dass dies eine wirksame Therapie darstellen könnte [62].

Bei der Behandlung opportunistischer Infektionen des ZNS ist das Risiko in Korrelation zum Immunstatus, ein IRIS zu entwickeln, zu berücksichtigen. Dieses Risiko scheint für die opportunistischen Infektionen des ZNS unterschiedlich zu sein [63].

\section{Bedeutung von Komorbiditäten}

$\nabla$

Durch die in den letzten Jahrzehnten deutlich zunehmende Lebenserwartung und verbesserte Lebensqualität HIV-Infizierter treten Komorbiditäten immer mehr in den Vordergrund. Zum einen gewinnen „klassische“ Ko-Infektionen wie Hepatitis C oder Lues neue Beachtung, zum anderen werden auch andere alters- und nichtinfektiologisch bedingte Komorbiditäten wie Herz-Kreislauf-Erkrankungen, Osteoporose oder Krebs zu einem wichtigen Faktor. In der guten Kontrolle der Komorbiditäten entscheidet sich zum jetzigen Zeitpunkt häufig die Lebensdauer und Lebensqualität des einzelnen Patienten. Dies wird uns in Zukunft sicher noch häufiger beschäftigen und liegt zu großen Teilen auf internistischem und neurologischem Fachgebiet.

Die altersassoziierten, nicht übertragbaren Komorbiditäten beinhalten kardiovaskuläre Erkrankungen, Diabetes mellitus, chronische Lebererkrankungen, eingeschränkte Nierenfunktion und verschiedene Krebsformen sowie Osteoporose. 2008 waren über $50 \%$ der mit HIV infizierten Patienten in den USA über 50 Jahre alt [64]. Es wird angenommen, dass sich die Zahl der älteren HIV Patienten innerhalb der nächsten Dekade verdoppelt. Zwischen 50 und $70 \%$ der HIV-positiven Patienten hatten mindestens eine Komorbidität [65]. Hierbei ist besonders brisant, dass HIV-positive Patienten diese altersassoziierten, also „normalen“ Alterserkrankungen zwischen 5 und 10 Jahre früher bekommen als eine alters- und geschlechtsgematchte Vergleichsgruppe aus der Allgemeinbevölkerung [66]. Auch wenn man Rauchen, Substanzgebrauch und andere „Life-style“-bedingte Risikofaktoren aus diesem Vergleich herausnimmt, haben HIV-positive Patienten ein deutlich erhöhtes Risiko früher einen Herzinfarkt oder Schlaganfall zu erleiden als ihre HIV-negativen Altersgenossen [66]. Eine aktuelle Metaanalyse über 5 Studien mit insgesamt 89713 Teilnehmern zeigte, dass innerhalb von 5 Jahren Follow-up 1245 ischämische Schlaganfälle bei im Durchschnitt 46(46-50)-jährigen, überwiegend (70\%) männlichen Patienten auftraten [67]. Neben den klassischen Risikofaktoren wie Alter, arterielle Hypertonie, Rauchen, Hyperlipidämie und Vorhofflimmern konnte auch die RNA-Viruslast (Odds Ratio 1,10 [1,04-1,17]) im Serum

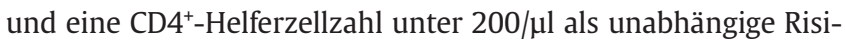
kofaktoren identifiziert werden [68]. Die Ursache für diese frühen kardiovaskulären Komplikationen bleibt weiterhin spekulativ. Eine vorzeitige oder übermäßige exogene Glykierung (Advanced Glycation Endproduct) von Proteinen, Lipiden und DNA wurde als Ursache für die vorzeitigen Alterungsprozesse disku- tiert. Eine erhöhte exogene Glykierung wurde bei HIV-negativen Patienten mit erhöhtem kardiovaskulären Risiko nachgewiesen. Als ein unabhängiger Risikofaktor wurden die Dauer der HIV-Infektion (OR 1,2 pro 5 Jahre) und der antiretroviralen Therapie (OR 1,35 pro 5 Jahre) identifiziert $[68,69]$.

HIV-positive Patienten haben ein höheres Risiko, bestimmte Krebsformen zu entwickeln als HIV-negative Menschen [70]. Hierbei unterscheiden sich AIDS-definierende Krebsformen wie das Kaposi-Sarkom oder das Non-Hodgkin-Lymphom von nicht AIDS-definierenden Formen wie Lungenkarzinomen, Analkarzinomen, Leberkarzinomen und nicht-Melanom-bedingten Hauttumoren [71]. In den westlichen Industrieländern mit breitem Zugang zu medizinischer Versorgung und antiretroviraler Therapie sind selbstverständlich die nicht AIDS-definierenden Tumoren bedeutsamer. Eine große Rolle spielen hier die virusassoziierten Tumoren, z. B. in der Leber durch Hepatitis B und C, aber auch im Anal- und Genitalbereich durch humane Papillomaviren und die HIV-Infektion selbst, die durch die Immunsuppression und Inflammation die Entwicklung von Tumoren begünstigen soll [72]. Verhaltensfaktoren wie Rauchen (Lungenkarzinome), Alkoholmissbrauch (Leber- und Pankreaskarzinome) und vermehrte UV-Exposition (Hauttumoren) spielen ebenfalls eine Rolle [70]. Aufgrund gleicher Transmissionswege kommen HIV/HCV-Doppelinfektionen häufig vor. In Deutschland sind ca. 10000 (15\% aller HIV-Patienten), in den USA 240000 (30\% aller HIV-Infizierten) mit HCV koinfiziert [73]. Die wenigsten dieser Patienten sind adäquat therapiert und es wird angenommen, dass eine HCV-Koinfektion mit einem beschleunigten Verlauf der HIV-Infektion bei unbehandelten Patienten assoziiert sein könnte [74]. Neurologische Symptome finden bei HCV-Patienten mehr und mehr Beachtung.

Nach Einführung einer Meldepflicht für die Diagnose „Syphilis“ stieg die Zahl der Meldungen stark an, wobei in Deutschland in den letzten Jahren im Schnitt ca. 3500 Erkrankungen pro Jahr registriert wurden [75]. Es wird angenommen, dass ca. 80\% aller Fälle durch sexuelle Kontakte zwischen Männern auftreten (MSM), sodass bei vielen eine Koinfektion HIV/Lues besteht. Der Verlauf der Lues unterscheidet sich bei HIV-Infizierten von Patienten ohne HIV-Infektion, wobei der Verlauf bei Patienten mit HIV-Infektion wesentlich schneller ist und seltene Manifestationen wie Papillitis, Retinitis, Uveitis und Vaskulitis bereits sehr früh auftreten [76].

\section{Besonderheiten der Liquordiagnostik bei HIV und Aids $\nabla$}

Als neueres Verfahren der Liquoranalyse bei immunologischen Erkrankungen wie auch HIV und Aids gewinnt die Durchflusszytometrie zunehmend an Bedeutung [76, 77]. Durchflusszytometrische Analysen der Liquorzellen zeigen, dass die Pleozytose bei der HIV-Infektion mit Ausnahme von CD4+-T-Zellen alle Lymphozytensubpopulationen erfasst. Die Hauptkomponente nehmen dabei CD8 ${ }^{+}$-T-Zellen ein. Die CD4:CD8-Ratio ist im Liquor analog zum peripheren Blut stark erniedrigt. Darüber hinaus finden sich vermehrt NK-Zellen, B-Zellen und Plasmazellen. Außerdem lassen sich aktivierte $\mathrm{CD} 16^{+} \mathrm{CD} 69^{+}$Monozyten im Liquor nachweisen [77]. Höhere Gesamtleukozytenzahlen ( $>50 / \mu \mathrm{l})$ weisen auf andere HIV-assoziierte Erkrankungen wie opportunistische Infektionen hin, insbesondere, wenn die Zahl peripherer CD4 ${ }^{+}$-T-Zellen unter 200/ $\mu$ l sinkt. Dabei ist zu beachten, dass eine Schrankenstörung und oligoklonale Banden generell nicht zwischen primä- 
ren HIV-Neuromanifestationen und opportunistischen Infektionen differenzieren können [78, 79].

\section{Opportunistische Infektionen}

Wegweisend für eine sekundäre Neuromanifestation kann neben der Liquorzellzahl der Nachweis einer humoralen Reaktion von IgG, IgA und IgM sein, die bei opportunistischen, HIV-assoziierten ZNS-Infektionen in etwa der Hälfte der Fälle vorhanden ist. Diagnostisch entscheidend ist aber immer der direkte Erregernachweis aus dem Liquor, der wegen der unzuverlässigen Ausbildung einer spezifischen humoralen Immunantwort der Berechnung eines erregerspezifischen Antikörper-Indexes deutlich überlegen ist. Bei opportunistischen Infektionen bei HIV und Aids kommt daher der Detektion mikrobieller Genomsequenzen mittels Polymerasekettenreaktion (PCR) eine besondere diagnostische Bedeutung zu.

Eine Zytomegalie-Enzephalitis (CMV) tritt in der Regel bei CD4+T-Zellzahlen von $<50 / \mu l$ auf. In der Akutphase findet sich im Liquor häufig zunächst eine milde granulozytäre Pleozytose mit einer Erhöhung des Liquorproteins und normalen bis leicht erniedrigten Glukosewerten. Erst später zeigt sich das für virale Infektionen typische lymphomonozytäre Zellbild. Die CMV-Infektion kann mit hoher Sensitivität (80-90\%) und Spezifität (9095\%) mittels PCR nachgewiesen werden. Sehr sensitive PCR-Protokolle mit einer Nachweisgrenze $<10$ Kopien/ml Liquor können zur Differenzierung einer latenten von einer floriden CMV-Infektion herangezogen werden $[80,81]$.

Für den Nachweis des JC-Virus, dem Erreger der PML, liegt die Spezifität der PCR bei annähernd $90-100 \%$ und die Sensitivität bei 70-90\%, mit ultrasensitiven Techniken sogar bei 95\%. Die Sensitivität des Assays kann kritisch für die Diagnose einer PML sein. Eine negative Liquor-PCR schließt daher eine PML nicht aus. Eine Hirnbiopsie kann zur Sicherung der Diagnose erforderlich sein [82].

Das Risiko für die Entwicklung primärer ZNS-Lymphome steigt in späteren Krankheitsstadien einer HIV-Infektion an. Da diese fast immer mit einer Epstein-Barr-Virus (EBV)-Infektion assoziiert ist, hat die EBV-Diagnostik einen hohen Stellenwert bei primären ZNS-Lymphomen von AIDS-Patienten. Die EBV-DNA lässt sich mit einer Sensitivität von 80-90\% und einer Spezifität von 80 95\% im Liquor nachweisen $[83,84]$.

Auch bei opportunistischen Pilzinfektionen, allen voran bei der Kryptokokkenmeningitis, sind die Routineliquorparameter diagnostisch nicht wegweisend. Häufig findet sich eine Erhöhung des Liquordrucks $>50 \mathrm{cmH}_{2} \mathrm{O}$ als Ausdruck einer Liquorzirkulationsstörung. Die Glukose ist in der Regel erniedrigt, das Liquoreiweiß erhöht. Die Methode der Wahl für die rasche und zuverlässige Diagnose der Kryptokokkenmeningitis ist die Mikroskopie des nativen Liquors im Tuschepräparat innerhalb einer Stunde nach Punktion. Sie weist den Erreger durch Darstellung der charakteristischen bekapselten Hefezellen in 80 - 90\% der Fälle nach. Beweisend für eine Kryptokokkose des Nervensystems ist der Latex-Antigen-Schnelltest zum Nachweis von Kapselpolysaccharid von C. neoformans bzw. C. gattii oder die Kultur der Erreger. Jeder Antigennachweis - unabhängig von der Höhe des Titers - ist bis zum Beweis des Gegenteils als Zeichen einer bestehenden oder kürzlich abgelaufenen Kryptokokkose zu werten [85, 86].

Eine weitere, typische opportunistische Infektion ist die Neurotuberkulose. Im Liquor finden sich ein deutlich erhöhtes Eiweiß bis $1000 \mathrm{mg} / \mathrm{dl}$ bei primär spinaler Krankheitslokalisation, eine

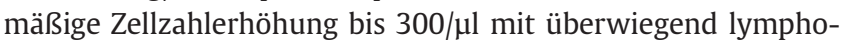
zytärem, inital gemischtzelligem Zellbild mit polymorphkerni- gen und mononukleären Zellen sowie eine erniedrigte Liquorglukose (Liquor/Blut $<0,5$ ) bei erhöhtem Liquorlaktat. Der Anteil an eosinophilen Granulozyten kann bis zu 20\% ausmachen. Eine Schrankenfunktionsstörung sowie eine intrathekale IgA-Synthese (QIgA>QIgG) gelten als charakteristisch. Die Sensitivität der Mikroskopie nach Ziehl-Nehlsen liegt bei weniger als $10 \%$ und die Chance auf eine kulturelle Erregeranzucht bei weniger als $20 \%$. Am sensitivsten ist noch der PCR-Nachweis von mykobakterieller Nukleinsäure mit maximal $50 \%$ Sensitivität bei repetitiven Untersuchungen $[87,88]$.

Nicht selten findet sich eine Koinfektion mit Treponema pallidum bei HIV-Patienten. In erster Linie handelt es sich um eine syphilitische Meningitis oder eine meningovaskuläre Syphilis. Im Liquor zeigen sich eine mäßige Pleozytose mit durchschnittlichen Zell-

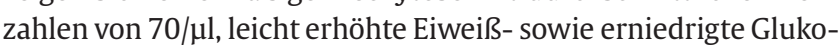
sewerte. Die serologische Diagnostik erfolgt nach einem Stufenschema. Als Suchtest wird die Treponema-pallidum-Partikel-Agglutination (TPPA) oder ein IgG-spezifischer Enzymimmunoassay (IgG-EIA) eingesetzt. Es schließt sich als Bestätigungstest der Treponema-pallidum-Antikörper-Fluoreszenz-Test (FTA-Abs-IgG) bzw. ein spezifischer IgG-Immunoblot an. Zur Verlaufskontrolle und Hinweis auf die Akuität der Infektion dienen der VDRL-Test („venereal research laboratory test“) oder der FTA-Abs-IgM, IgMEIA bzw. Immunoblot. Die Abgrenzung gegenüber kreuzreagierenden Borrelienantikörpern gelingt mithilfe spezifischer Immunoblots mit hoher Zuverlässigkeit. Der Nachweis einer intrathekalen Treponemenantikörpersynthese wird durch die Bestimmung des intrathekal produzierten Treponema-pallidum-Antikörper-Index ITpA geführt. Dabei sind ITpA-Werte über 3,0 beweisend für eine intrathekale Antikörpersynthese gegen Treponemen. Der Nachweis einer intrathekalen Synthese von Treponemen-Antikörpern spricht aber nicht immer für das Vorliegen einer floriden Neurolues. Auch bei ausgeheilten bzw. ausreichend therapierten Residualzuständen persistiert eine intrathekale Antikörpersynthese oft über Jahre. Zur Beurteilung der Krankheitsaktivität und Therapiebedürftigkeit sind daher auch nicht erregerspezifische Kriterien wie die Zellzahl und -differenzierung im Liquor sowie die Schrankenfunktion zu berücksichtigen. Nach erfolgreicher antibiotischer Therapie sind Zellzahl und Schrankenfunktionsstörung innerhalb von Wochen bis Monaten, der VDRL und das Treponemen-IgM innerhalb eines Jahres rückläufig [91, 92].

Die zerebrale Toxoplasmose ist eine der häufigsten opportunistischen Infektionen bei Patienten mit AIDS und einer CD4+-T-Zellzahl $<100 / \mu l$. Die Toxoplasma-PCR hat nur geringe bis moderate Sensitivität (12-64\%), wobei die Spezifität bei annähernd 100\% liegt. Ein negativer Befund schließt eine zerebrale Toxoplasmose nicht aus, sodass im Verdachtsfall und passender MRT-Bildgebung eine Therapie eingeleitet werden sollte [91, 92].

\section{Biomarker der HIV-Infektion}

Einen hohen Stellenwert für die Beurteilung des Krankheitsbzw. Therapieverlaufs nimmt die Analyse spezifischer Biomarker ein $[93,96]$. Ein wertvoller Marker ist die Bestimmung der HIV-1RNA im Liquor. Diese kann bereits bei klinisch-neurologisch unauffälligen Patienten nachgewiesen werden und kann bei intakter Blut-Hirn-Schranke auf eine lokale, intrazerebrale Replikation des Virus hinweisen. Im Rahmen dieser Kompartmentbildung haben etwa 16-20\% aller asymptomatischen HIV-Patienten eine stärkere Virusreplikation im Liquor als im Blut [93]. Bei unbehandelten, asymptomatischen Patienten bleibt die HIV-1-RNA im Liquor über Jahre relativ konstant (> 50 Kopien/ml), steigt aber 
Tab. 3 Liquorbiomarker bei HIV-Infektion.

\begin{tabular}{|c|c|c|}
\hline Klassifikation & Hauptmarker & zusätzliche Marker \\
\hline Virusmarker & HIV-1 RNA & $\begin{array}{l}\text { genetische HIV-Varianten, Medi- } \\
\text { kamentenresistenz, HIV-Kore- } \\
\text { zeptorexpression }\end{array}$ \\
\hline Immunmarker & Neopterin & $\begin{array}{l}\text { CCL2 (MCP-1), CXCL10 (IP10), } \\
\beta 2-\text { Mikroglobulin, IL-1ß, IL-6, } \\
\text { TNF- } \alpha \text {, löslicher TNF-Rezeptor II, } \\
\text { L-Selektin (CD62L), PD-1, MMP3, } \\
\text { MMP9, Iösliches CD14, Iösliches } \\
\text { ICAM-1, Quinolinsäure, plätt- } \\
\text { chenaktivierender Faktor (PAF) }\end{array}$ \\
\hline $\begin{array}{l}\text { neuronale } \\
\text { Marker }\end{array}$ & Neurofilament-L & $\begin{array}{l}\text { Gesamt-Tau-Protein, } \beta \text {-Amyloid, } \\
\text { S100 } \beta\end{array}$ \\
\hline
\end{tabular}

bei Patienten mit einer HIV-Enzephalopathie signifikant an, wobei die höchsten Werte bei der HIV-assoziierten Demenz und der akuten HIV-Meningoenzephalitis erreicht werden [94, 95]. Neben der HIV-1-RNA als viralem Biomarker können noch weitere Parameter für die Krankheitsaktivität herangezogen werden. Dazu zählt insbesondere das Neopterin als Marker der Makrophagenaktivierung. Die Konzentration des Neopterins korreliert mit dem HIV-1-RNA-Spiegel im Liquor. Bei unbehandelten HIVPatienten finden sich meist schon erhöhte Neopterinspiegel im Liquor, die deutlich ansteigen können, wenn die Immunsuppression durch HIV zunimmt und die Zahl an $\mathrm{CD}^{+}$-T-Zellen im peripheren Blut sinkt [12]. Neben dem Neopterin sind noch eine Reihe anderer Immunaktivierungsmarker beschrieben worden ( Tab.3). Dazu zählen Interleukine wie IL-1 $\beta$, IL-6 und die Chemokine MCP-1 (CCL2) oder CXCL10 (IP10), das von aktivierten Makrophagen sezerniert wird und den Übertritt von Leukozyten aus der Blutbahn ins ZNS fördert [96].

Als Marker der neuronalen Schädigung des HI-Virus kann das Neurofilament-Leichtprotein (Neurofilament-L) herangezogen werden. Dieses Intermediärfilament kommt vorwiegend in großen, myelinisierten Neuronen vor und ist für die strukturelle Integrität von Axonen mit großen Kalibern maßgeblich verantwortlich. Eine erhöhte Konzentration des Neurofilament-L lässt sich bereits bei unbehandelten HIV-Patienten mit milden neurokognitiven Defiziten im Liquor nachweisen. In fortgeschrittenen Stadien der HIV-Infektion und bei HIV-assoziierter Demenz finden sich zudem erhöhte Konzentrationen des Gesamt-Tau-Proteins als neuronaler Schädigungsmarker, wobei die Spiegel signifikant mit der Viruslast der Patienten und schweren globalen Veränderungen der weißen Substanz im MRT korrelieren [97].

\section{Effekte einer hochaktiven antiretroviralen \\ Kombinationstherapie (cART)}

Unter einer suffizienten cART lassen sich eine Reihe von Veränderungen der Liquorparameter beobachten. Die Viruslast (HIVRNA) im Blut und Liquor wird durch die cART deutlich vermindert und sinkt in der Regel unter die Nachweisgrenze der klinischen Assays (<20 Kopien/ml). Einhergehend mit dem Abfall der HI-Viruslast sinkt die Gesamtleukozytenzahl im Liquor und hier insbesondere die Zahl der CD8+-T- und B-Zellen, während sich die Zahl der $C D 4^{+}-T-Z e l l e n$ nicht signifikant ändert [77]. Die Schrankenstörung und der abnorme IgG-Index bleiben aber bei mehr als 40\% der HIV-Patienten bestehen. Immunmarker wie

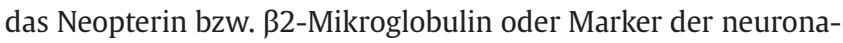
len Schädigung wie das Neurofilament-L fallen unter der Langzeitbehandlung mit einer cART signifikant ab oder normalisieren sich langsam $[98,99]$. Die andauernde Immunaktivierung im ZNS wird als prädisponierender Faktor für die Entwicklung HIV-assoziierter neurokognitiver Störungen angesehen. Darüber hinaus kommt es unter der cART im Langzeitverlauf bei bis zu 10\% der Patienten zur Ausbildung isolierter HIV-Varianten, die sich hinsichtlich ihres Therapieansprechens von dem HI-Virus in der Peripherie deutlich unterscheiden und auch einen verstärkten Tropismus von infizierten Makrophagen/Monozyten ins Gehirn bewirken können $[100,101]$.

\section{Interessenkonflikt}

$\nabla$

K. Hahn: Drittmittel: ehemals Glaxo (jetzt ViiV) . Referententätigkeit/Reisekosten: Astellas, Gilead, ViiV, Abvie (bzw. Abbott), CSL Behring, Pfizer. M. Maschke: Honorare für Vorträge und Advisory Boards von Allergan Pharm, Biogen Idec, Novartis, UCB, Boehringer Ingelheim, Bayer, Ipsen Pharma. I. W. Husstedt: Advisory Board von Abbott, Astellas, Boehringer, BMS; Honorare für Vorträge von Astra, Boehringer, BMS, GSK, Gilead, Pfizer, Grünenthal, MSD, Behring; research funding from Gilead for investigator initiated study. G. Arendt und O. Grauer geben an, dass kein Interessenkonflikt besteht. Mark Obermann hat finanzielle Unterstützung für Forschungsprojekte und/oder Honoraria von Biogen Idec, Novartis, Sanofi-Aventis, Genzyme, Pfizer, Teva und Heel erhalten. Er hat des Weiteren Forschungsstipendien von Allergan, Electrocore und dem Bundesministerium für Bildung und Forschung (BMBF) erhalten.

\section{Literatur}

1 McArthur JC. Dementia, neuropathy, and HIV. An interview with Justin C. McArthur, MB, BS, MPH. Interview by Mark Mascolini. J Int Assoc Physicians AIDS Care 1996; 2: 27-28, 31-24

2 Tozzi V, Balestra P, Serraino D et al. Neurocognitive impairment and survival in a cohort of HIV-infected patients treated with HAART. AIDS Res Hum Retroviruses 2005; 21: 706 - 713

3 Valcour VG, Sithinamsuwan P, Nidhinandana S et al. Neuropsychological abnormalities in patients with dementia in CRF 01_AE HIV-1 infection. Neurology 2007; 68: 525-527

4 Antinori A, Arendt G, Becker JT et al. Updated research nosology for HIV-associated neurocognitive disorders. Neurology 2007; 69: $1789-1799$

5 Arendt G, Orhan E, Arbter $P$ et al. Prospective Multicentric Evaluation of a Screening Questionaire as an Entry Tool for Neuropsychological Short Testing in HIV/AIDS-Patients. Melbourne: World AIDS-Congress; 2014

6 The Mind Exchange Workung G. Assessment, Diagnosis, and Treatment of HIV-Associated Neurocognitive Disorder: A Consensus Report of the Mind Exchange Program. Clin Infect Dis 2013; 56: 10041017

7 Clifford DB, Evans S, Yang $Y$ et al. Long-term impact of efavirenz on neuropsychological performance and symptoms in HIV-infected individuals (ACTG 5097s). HIV Clin Trials 2009; 10: 343-355

8 McArthur JC, Brew BJ, Nath A. Neurological complications of HIV infection. Lancet Neurol 2005; 4: 543-555

9 Chang L, Ernst T, Leonido-Yee $M$ et al. Cerebral metabolite abnormalities correlate with clinical severity of HIV-1 cognitive motor complex. Neurology 1999; 52: 100-108

10 Winston A, Duncombe C, Li PC et al. Two patterns of cerebral metabolite abnormalities are detected on proton magnetic resonance spectroscopy in HIV-infected subjects commencing antiretroviral therapy. Neuroradiology 2012; 54: 1331 - 1339

11 Marshall DW. HIV penetration of the BBB. Neurology 1988; 38: $1000-1001$

12 Hagberg L, Cinque P, Gisslen $M$ et al. Cerebrospinal fluid neopterin: an informative biomarker of central nervous system immune activation in HIV-1 infection. AIDS Res Ther 2010; 7: 15 
13 Abdulle S, Mellgren A, Brew BJ et al. CSF neurofilament protein (NFL) a marker of active HIV-related neurodegeneration. J Neurol 2007; 254: $1026-1032$

14 Arendt G, Nolting T, Frisch C et al. Intrathecal viral replication and cerebral deficits in different stages of human immunodeficiency virus disease. J Neurovirol 2007; 13: 225-232

15 Gupta G. Current concepts in HIV pathogenesis and treatment. J Calif Dent Assoc 2001; 29: 129-135

16 Heaton RK, Franklin DR, Ellis RJ et al. HIV-associated neurocognitive disorders before and during the era of combination antiretroviral therapy: differences in rates, nature, and predictors. J Neurovirol 2011; 17: 3-16

17 Pozniak A, Rackstraw S, Deayton J et al. HIV-associated neurocognitive disease: case studies and suggestions for diagnosis and management in different patient subgroups. Antivir Ther 2014; 19: 1 -13

18 Cysique LA, Letendre SL, Ake C et al. Incidence and nature of cognitive decline over 1 year among HIV-infected former plasma donors in China. AIDS (London, England) 2010; 24: 983-990

19 Shiramizu B, Ananworanich J, Chalermchai T et al. Failure to clear intra-monocyte HIV infection linked to persistent neuropsychological testing impairment after first-line combined antiretroviral therapy. J Neurovirol 2012; 18: 69-73

20 Cysique LA, Brew BJ. Neuropsychological functioning and antiretroviral treatment in HIV/AIDS: a review. Neuropsychol Rev 2009; 19 : 169-185

21 Letendre S, Marquie-Beck J, Capparelli E et al. Validation of the CNS Penetration-Effectiveness rank for quantifying antiretroviral penetration into the central nervous system. Arch Neurol 2008; 65: 6570

22 Schweinsburg BC, Taylor MJ, Alhassoon OM et al. Brain mitochondrial injury in human immunodeficiency virus-seropositive (HIV+) individuals taking nucleoside reverse transcriptase inhibitors. J Neurovirol 2005; 11: $356-364$

23 Spector SA, Singh KK, Gupta $S$ et al. APOE epsilon4 and MBL-2 O/O genotypes are associated with neurocognitive impairment in HIV-infected plasma donors. AIDS (London, England) 2010; 24: 1471 - 1479

24 Wachtman LM, Skolasky RL, Tarwater PM et al. Platelet decline: an avenue for investigation into the pathogenesis of human immunodeficiency virus-associated dementia. Arch Neurol 2007; 64: 12641272

25 Centner CM, Bateman KJ, Heckmann JM. Manifestations of HIV infection in the peripheral nervous system. Lancet Neurol 2013; 12: 295-309

26 Arenas-Pinto A, Bhaskaran K, Dunn D et al. The risk of developing peripheral neuropathy induced by nucleoside reverse transcriptase inhibitors decreases over time: evidence from the Delta trial. Antivir Ther 2008; 13: 289-295

27 Ellis RJ, Rosario D, Clifford DB et al. Continued high prevalence and adverse clinical impact of human immunodeficiency virus-associated sensory neuropathy in the era of combination antiretroviral therapy: the CHARTER Study. Arch Neurol 2010; 67: 552-558

28 Hahn $K$, Robinson B, Anderson $C$ et al. Differential effects of HIV infected macrophages on dorsal root ganglia neurons and axons. Exp Neurol 2008; 210: 30-40

29 Hao S. The Molecular and Pharmacological Mechanisms of HIV-Related Neuropathic Pain. Curr Neuropharmcol 2013; 11: 499-512

30 Bhangoo SK, Ren D, Miller RJ et al. CXCR4 chemokine receptor signaling mediates pain hypersensitivity in association with antiretroviral toxic neuropathy. Brain Behav Immun 2007; 21: 581-591

31 Bhangoo SK, Ripsch MS, Buchanan DJ et al. Increased chemokine signaling in a model of HIV1-associated peripheral neuropathy. Molecular Pain 2009; 5: 48

32 Huang $W$, Zheng $W$, Ouyang $H$ et al. Mechanical allodynia induced by nucleoside reverse transcriptase inhibitor is suppressed by p55TNFSR mediated by herpes simplex virus vector through the SDF1 alpha/ CXCR4 System in rats. Anesth Analg 2014; 118: 671-680

33 Hahn K, Arendt G, Braun JS et al. A placebo-controlled trial of gabapentin for painful HIV-associated sensory neuropathies. J Neurol 2004; 251: $1260-1266$

34 Hahn K, Husstedt IW. [HIV-associated neuropathies]. Nervenarzt 2010; 81: 409-417

35 Simpson DM, Brown S, Tobias J. Controlled trial of high-concentration capsaicin patch for treatment of painful HIV neuropathy. Neurology 2008; 70: $2305-2313$
36 Martin C, Solders G, Sonnerborg A et al. Antiretroviral therapy may improve sensory function in HIV-infected patients: a pilot study. Neurology 2000; 54: 2120-2127

37 Brannagan TH 3rd, Zhou Y. HIV-associated Guillain-Barre syndrome. J Neurol Sci 2003; 208: 39-42

38 Thornton CA, Latif AS, Emmanuel JC. Guillain-Barre syndrome associated with human immunodeficiency virus infection in Zimbabwe. Neurology 1991; 41: $812-815$

39 Gardner K, Hall PA, Chinnery PF et al. HIV treatment and associated mitochondrial pathology: review of 25 years of in vitro, animal, and human studies. Toxicol Pathol 2014; 42: 811 - 822

40 Rodkjaer L, Laursen T, Balle $N$ et al. Depression in patients with HIV is under-diagnosed: a cross-sectional study in Denmark. HIV Med 2010; $11: 46-53$

41 Husstedt IW, Arendt G. HIV und ZNS Management neurologischer Erkrankungen. 2. Aufl. Königswinter: Immedis-Verlag; 2012

42 Cruess DG, Evans DL, Repetto MJ et al. Prevalence, diagnosis, and pharmacological treatment of mood disorders in HIV disease. Biol Psychiatry 2003; 54: $307-316$

43 Ickovics JR, Hamburger ME, Vlahov D et al. Mortality, CD4 cell decline, and depressive symptoms among HIV-seropositive women: longitudinal analysis from the HIV Epidemiology Research Study. JAMA 2001; 285: $1466-1477$

44 Smith C, Ryom L, Monforte A et al. Lack of association between use of efavirenz and death from suicide: evidence from the D:A:D study. J Int Aids Soc 2014; 17 (Suppl. 03): 19512 eCollection

45 Schuster R, Bornovalova M, Hunt E. The influence of depression on the progression of HIV: direct and indirect effects. Behav Modif 2012; 36: $123-145$

46 Kaestner F, Anneken K, Mostert $C$ et al. Depression associated with antiretroviral drug therapy in HIV: case report and overview. Int J STD AIDS 2012; 23: e14-19

47 Pieper AA, Treisman GJ. Drug treatment of depression in HIV-positive patients: safety considerations. Drug Saf 2005; 28: $753-762$

48 Horberg MA, Silverberg MJ, Hurley $L B$ et al. Effects of depression and selective serotonin reuptake inhibitor use on adherence to highly active antiretroviral therapy and on clinical outcomes in HIV-infected patients. J Acquir Immune Defic Syndr (1999) 2008; 47: 384-390

49 Owe-Larsson B, Sall L, Salamon E et al. HIV infection and psychiatric illness. Afr J Psychiatry 2009; 12: 115-128

50 Buchacz K, Baker RK, Palella FJJr et al. AIDS-defining opportunistic illnesses in US patients, 1994-2007: a cohort study. AIDS (London, England) 2010; 24: 1549-1559

51 French MA, Price $P$, Stone $S F$. Immune restoration disease after antiretroviral therapy. AIDS (London, England) 2004; 18: 1615-1627

52 Goebel FD. Immune reconstitution inflammatory syndrome (IRIS) another new disease entity following treatment initiation of HIV infection. Infection 2005; 33: 43-45

53 Committee UKCHCSS, Garvey L, Winston A et al. HIV-associated central nervous system diseases in the recent combination antiretroviral therapy era. Eur J Neurol 2011; 18: 527-534

54 Tan IL, Smith BR, von Geldern G et al. HIV-associated opportunistic infections of the CNS. Lancet Neurol 2012; 11: 605-617

55 Day JN, Chau TT, Lalloo DG. Combination antifungal therapy for cryptococcal meningitis. N Engl J Med 2013; 368: 2522 - 2523

56 Schneider-Hohendorf T, Philipp K, Husstedt IW et al. Specific loss of cellular L-selectin on CD4(+) T cells is associated with progressive multifocal leukoencephalopathy development during HIV infection. AIDS (London, England) 2014; 28: 793-795

57 Hoffmann C, Horst HA, Albrecht $\mathrm{H}$ et al. Progressive multifocal leucoencephalopathy with unusual inflammatory response during antiretroviral treatment. J Neurol Neurosurg Psychiatry 2003; 74: $1142-1144$

58 Martin-Blondel G, Bauer J, Cuvinciuc Vet al. In situ evidence of JC virus control by CD8+ T cells in PML-IRIS during HIV infection. Neurology 2013; 81: 964-970

59 Sahraian MA, Radue EW, Eshaghi A et al. Progressive multifocal leukoencephalopathy: a review of the neuroimaging features and differential diagnosis. Eur J Neurol 2012; 19: 1060-1069

60 Longley N, Harrison TS, Jarvis JN. Cryptococcal immune reconstitution inflammatory syndrome. Curr Opin Infect Dis 2013; 26: 26-34

61 Skiest DJ, Hester LJ, Hardy RD. Cryptococcal immune reconstitution inflammatory syndrome: report of four cases in three patients and review of the literature. J Infect 2005; 51: e289-297 
62 Giacomini PS, Rozenberg A, Metz I et al. Maraviroc and JC virus-associated immune reconstitution inflammatory syndrome. N Eng J Med 2014; 370: $486-488$

63 Lawn SD, Meintjes G. Pathogenesis and prevention of immune reconstitution disease during antiretroviral therapy. Expert Rev Anti Infect Ther 2011; 9: 415-430

64 Harrison KM, Song $R$, Zhang $X$. Life expectancy after HIV diagnosis based on national HIV surveillance data from 25 states, United States. J Acquir Immune Defic Syndr 2010; 53: 124-130

65 Friis-Moller $N$, Weber $R$, Reiss $P$ et al. Cardiovascular disease risk factors in HIV patients - association with antiretroviral therapy. Results from the DAD study. Aids 2003; 17: 1179-1193

66 Grunfeld C, Delaney JA, Wanke C et al. Preclinical atherosclerosis due to HIV infection: carotid intima-medial thickness measurements from the FRAM study. Aids 2009; 23: 1841 -1849

67 D’Ascenzo F, Quadri G, Cerrato E et al. A meta-analysis investigating incidence and features of stroke in HIV-infected patients in the highly active antiretroviral therapy era. J Cardiovasc Med 2014; Doi: 10.2459/JCM.0b013e328365ca31

68 Krishnan S, Schouten JT, Atkinson B et al. Metabolic syndrome before and after initiation of antiretroviral therapy in treatment-naive HIVinfected individuals. JJ Acquir Immune Defic Syndr 2012; 61: 381 389

69 Schouten JN, Van der Ende ME, Koeter T et al. Risk factors and outcome of HIV-associated idiopathic noncirrhotic portal hypertension. Aliment Pharmacol Ther 2012; 36: 875-885

70 Engels EA. Non-AIDS-defining malignancies in HIV-infected persons: etiologic puzzles, epidemiologic perils, prevention opportunities. Aids 2009; 23: 875-885

71 Mani D, Haigentz M Jr, Aboulafia DM. Lung cancer in HIV Infection. Clin Lung Cancer 2012; 13: 6-13

72 Silverberg MJ, Abrams DI. AIDS-defining and non-AIDS-defining malignancies: cancer occurrence in the antiretroviral therapy era. Curr Opin Oncol 2007; 19: 446-451

73 Kim AY, Onofrey S, Church DR. An epidemiologic update on hepatitis C infection in persons living with or at risk of HIV infection. J Infect Dis 2013; 207 (Suppl. 01): S1 - 6

74 Murray J, Fishman SL, Ryan E et al. Clinicopathologic correlates of hepatitis C virus in brain: a pilot study. J Neurovirol 2008; 14: 17-27

75 Institut RK. Syphilis Infektionen in Deutschland. Epidemiol Bulletin 2012: 48

76 Conde-Sendin MA, Amela-Peris R, Aladro-Benito Yet al. Current clinica spectrum of neurosyphilis in immunocompetent patients. Eur Neurol 2004; 52: 29-35

77 Ho EL, Ronquillo R, Altmeppen $\mathrm{H}$ et al. Cellular Composition of Cerebrospinal Fluid in HIV-1 Infected and Uninfected Subjects. PLoS One 2013; 8: e66188

78 Arendt G, Nolting T. [Neurological complications of HIV infection]. Nervenarzt 2008; 79: 1449 - 1462; 1463

79 Letendre SL, Ellis RJ, Ances BM et al. Neurologic complications of HIV disease and their treatment. Top HIV Med 2010; 18: 45 - 55

80 Stanojevic $M$, Zerjav $S$, Jevtovic $D$ et al. CMV DNA in blood and CSF of HIV infected patients. Virus Res 2002; 85: 117-122

81 Maschke M, Kastrup O, Diener HC. CNS manifestations of cytomegalovirus infections: diagnosis and treatment. CNS Drugs 2002; 16: $303-$ 315

82 Wyen C, Hoffmann C, Schmeisser N et al. Progressive multifocal leukencephalopathy in patients on highly active antiretroviral therapy: survival and risk factors of death. J Acquir Immune Defic Syndr 2004; 37: $1263-1268$

83 Ambinder RF. Epstein-Barr virus associated lymphoproliferations in the AIDS setting. Eur J Cancer 2001; 37: 1209-1216

84 Bossolasco S, Cinque P, Ponzoni $M$ et al. Epstein-Barr virus DNA load in cerebrospinal fluid and plasma of patients with AIDS-related lymphoma. J Neurovirol 2002; 8: $432-438$

85 Chuck SL, Sande MA. Infections with Cryptococcus neoformans in the acquired immunodeficiency syndrome. N Engl J Med 1989; 321: $794-799$

86 Bicanic T, Wood R, Bekker LG et al. Antiretroviral roll-out, antifungal roll-back: access to treatment for cryptococcal meningitis. Lancet Infect Dis 2005; 5: 530 - 531

87 Marx GE, Chan ED. Tuberculous meningitis: diagnosis and treatment overview. Tuberc Res Treat 2011; 2011: 798764

88 Brancusi F, Farrar J, Heemskerk D. Tuberculous meningitis in adults: a review of a decade of developments focusing on prognostic factors for outcome. Future Microbiol 2012; 7: 1101 -1116

89 Marra CM, Maxwell CL, Smith SL et al. Cerebrospinal fluid abnormalities in patients with syphilis: association with clinical and laboratory features. J Infect Dis 2004; 189: 369 - 376

90 Poliseli R, Vidal JE, Penalva De Oliveira AC et al. Neurosyphilis in HIVinfected patients: clinical manifestations, serum venereal disease research laboratory titers, and associated factors to symptomatic neurosyphilis. Sex Transm Dis 2008; 35: 425-429

91 Cingolani A, De Luca A, Ammassari A et al. PCR detection of Toxoplasma gondii DNA in CSF for the differential diagnosis of AIDS-related focal brain lesions. J Med Microbiol 1996; 45: 472-476

92 Arendt G, von Giesen HJ, Hefter $H$ et al. Long-term course and outcome in AIDS patients with cerebral toxoplasmosis. Acta Neurol Scand 1999; 100: 178 - 184

93 Price RW, Peterson J, Fuchs D et al. Approach to cerebrospinal fluid (CSF) biomarker discovery and evaluation in HIV infection. J Neuroimmune Pharmacol 2013; 8: 1147 - 1158

94 Clifford DB, Ances BM. HIV-associated neurocognitive disorder. The Lancet infectious diseases 2013; 13: 976-986

95 Ellis RJ, Moore DJ, Childers ME et al. Progression to neuropsychological impairment in human immunodeficiency virus infection predicted by elevated cerebrospinal fluid levels of human immunodeficiency virus RNA. Arch Neurol 2002; 59: 923 -928

96 Valcour V, Chalermchai T, Sailasuta $N$ et al. Central nervous system viral invasion and inflammation during acute HIV infection. J Infect Dis 2012; 206: 275 - 282

97 Steinbrink F, Evers S, Buerke B et al. Cognitive impairment in HIV infection is associated with MRI and CSF pattern of neurodegeneration. Eur J Neurol 2013; 20: 420-428

98 Spudich SS, Nilsson AC, Lollo ND et al. Cerebrospinal fluid HIV infection and pleocytosis: relation to systemic infection and antiretroviral treatment. BMC Infect Dis 2005; 5: 98

99 Yilmaz A, Yiannoutsos CT, Fuchs D et al. Cerebrospinal fluid neopterin decay characteristics after initiation of antiretroviral therapy. J Neuroinflamm 2013; 10: 62

100 Dunfee RL, Thomas ER, Gorry PR et al. The HIV Env variant N283 enhances macrophage tropism and is associated with brain infection and dementia. Proc Natl Acad Sci U S A 2006; 103: 15160-15165

101 Stam AJ, Nijhuis M, van den Bergh WM et al. Differential genotypic evolution of HIV-1 quasispecies in cerebrospinal fluid and plasma: a systematic review. AIDS Rev 2013; 15: 152 - 161 